\title{
Endocrine and Paracrine Regulation of Endometrial Angiogenesis
}

\author{
ROBERT N. TAYLOR, ${ }^{a}$ DAN I. LEBOVIC,${ }^{a, b}$ DANIELA HORNUNG, ${ }^{a, c}$ AND \\ MICHAEL D. MUELLER ${ }^{a, d}$ \\ ${ }^{a}$ Center for Reproductive Sciences, Department of Obstetrics, Gynecology and \\ Reproductive Sciences, University of California, San Francisco, California \\ 94143-0556, USA \\ ${ }^{b}$ University of Michigan, School of Medicine, Ann Arbor, Michigan 48109, USA \\ ${ }^{c}$ University of Tübingen, Tübingen, Germany \\ ${ }^{d}$ University of Berne, Berne, Switzerland
}

\begin{abstract}
The human endometrium is a complex tissue comprised of different cell types, including epithelial, stromal, inflammatory, perivascular, and blood vessel cells. The hormonal receptivity and distribution of these cell populations change during the menstrual cycle. Cyclical endometrial growth is dependent on its ability to regenerate a vascular capillary network, which grows in parallel with the proliferation and differentiation of the endometrial lining. Natural hormonal effects on the endometrium and endocrine manipulation of this tissue, in response to the use of exogenous steroid therapies, can affect endometrial capillary proliferation and function, leading to clinical abnormalities of uterine bleeding. We propose that the regulation of endometrial angiogenesis is mediated indirectly via complex interactions among cell types. Our laboratory has focused on a prototypical member of the angiogenic proteins, vascular endothelial growth factor (VEGF)-A. In this paper we present data demonstrating that VEGF-A expression in normal endometrial epithelial and stromal cells and in Ishikawa adenocarcinoma cells is increased by an ovarian steroid, estradiol. Infiltrating immune cells, particularly polymorphonuclear granulocytes, also are sources of VEGF-A. In inflammatory conditions involving the endometrium (e.g., endometriosis), a proinflammatory cytokine, IL-1ß, can mediate neoangiogenesis by inducing VEGF-A gene transcription. Thus, endometrial vascularization is effected by both endocrine and paracrine pathways.
\end{abstract}

KEYWORDS: cytokines; steroids; uterus; VEGF

\section{INTRODUCTION}

Endometrial angiogenesis, as with neovascularization in other sites, requires the sprouting of new capillaries from preexisting vessels. This complex process involves the proteolytic degradation of extracellular matrix, the proliferation and migration of endothelial cells, and ultimately the formation of patent capillary tubules supply-

Address for correspondence: Robert N. Taylor, M.D., Ph.D., Director, Center for Reproductive Sciences, University of California, San Francisco, San Francisco, CA 94143-0556. Voice: 415476-4556; fax: 415-753-3271.

rtaylor@socrates.ucsf.edu 
ing the growing endometrium. Few normal adult tissues are as dynamic as the human endometrium, whose thickness grows up to 10-fold each month after menstrual desquamation. The precise regulation of its vascularization, critical to endometrial perfusion, embryonic implantation, and survival of the species, is understood poorly. Many growth factors and cytokines have been shown to exert chemotactic, mitogenic, or inhibitory activity on endothelial cells, smooth muscle cells, and pericytes and to participate in angiogenic processes either directly or indirectly. As angiogenesis occurs when the balance of local factors promoting vascular growth exceeds the action of vascular inhibitors, several different regulatory mechanisms are possible. In this paper we focus on the upregulation of a prototypical angiogenic factor, vascular endothelial growth factor (VEGF)-A, as a key mediator of neovascularization.

Several pleiotropic growth factors (e.g., basic FGF, PDGF, TGF- $\beta$, and interleukin [IL]-6) have been shown to exert angiogenic activities. ${ }^{1}$ By contrast, the $43-\mathrm{kD}$, dimeric, heparin-binding glycoprotein VEGF-A is specifically mitogenic for endothelial cells, ${ }^{2}$ and VEGF receptors are restricted primarily to endothelial and trophoblast cells. Five molecular species of VEGF-A have been identified to date

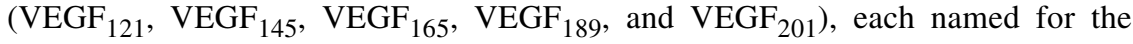
length of its amino acid sequence. The different mature proteins arise via alternative splicing of a single primary mRNA transcript. The dominant VEGF-A mRNA transcripts expressed by human endometrium and primary human endometrial cells encode the $\mathrm{VEGF}_{165}{ }^{3}$ and $\mathrm{VEGF}_{121}{ }^{4}$ proteins.

Cyclical vascular changes within the primate endometrium were first documented in the classical experiments of Markee. ${ }^{5}$ Heterotopic transplants of rhesus endometrium into the anterior chamber of the eye could be observed directly in this model. The functionalis layer of endometrium is supplied by an end-arteriole, referred to as the spiral arteriole. Each arteriole is responsible for the perfusion of $\sim 4-7 \mathrm{~mm}^{2}$ of endometrium. These vessels, unlike the radial and basal arteries that feed them, are highly sensitive to ovarian steroids. The endometrial vascular architecture changes throughout the menstrual cycle, paralleling growth of the supporting epithelium and stroma. From days 0-25, there is a gradual increase in branching and coiling of spiral arterioles, corresponding to an increase in the length and coiling of endometrial glands. A decade later, in their landmark article, Noyes and colleagues ${ }^{6}$ reported effects of enhanced vascular permeability and perivascular edema during the human endometrial cycle, providing further evidence that steroids from the ovary orchestrate vascular responses in normal endometrium. Beginning in the late proliferative phase, under the influence of ovarian estradiol production, a complex subepithelial capillary plexus develops in the cycling endometrium. ${ }^{7}$ The capillary endothelial cells also acquire mitogenic activity, evidenced by $\left[{ }^{3} \mathrm{H}\right]$ thymidine incorporation in tissue explants obtained at this cycle phase. ${ }^{8}$ More recent morphometric evaluations of endometrial vessel formation indicate significant variation in endothelial cell proliferation within different regions of the uterus. Samples from hysterectomy specimens show that the endothelial cell proliferation index is significantly elevated in functionalis compared with basalis layer vessels. ${ }^{9}$

In the last decade it has become apparent that some steroid hormone actions on uterine tissues are not direct but are effected by paracrine mediators such as cytokines and growth factors. ${ }^{10}$ Cytokines are key mediators of intercellular communication within the immune system and can exert proliferative, cytostatic, chemoattractant, or differentiative effects on the surrounding endometrium. The cur- 
rent studies sought to evaluate the potential mechanisms of VEGF-A gene regulation vis-à-vis the neovascularization of normal endometrium and endometriotic implants. The in vitro models used in the following experiments were designed to test hormone and cytokine responses of cells from the endometrial functionalis layer. Primary cell cultures were derived from Pipelle biopsy material, which yields predominantly superficial endometrial glands and stroma. Transfected Ishikawa cell models were designed to approximate the ovarian steroid receptor phenotype of functionalis epithelium, which differs from that of the underlying basalis zones. ${ }^{11}$

\section{MATERIALS AND METHODS}

\section{Subjects and Specimens}

Normally menstruating women undergoing laparoscopy for various indications were recruited. Women who had taken oral contraceptives, hormonal supplements, or gonadotropin-releasing hormone $(\mathrm{GnRH})$ analogs over the previous 3 months were excluded. Control subjects were identified at laparoscopy for tubal sterilization or for assessment of pelvic pain in whom no visible evidence of pelvic pathology was found. Subjects with endometriosis were identified when laparoscopy revealed the presence of classical or atypical endometriotic lesions. Clinical staging of endometriosis followed the revised modification of the American Fertility Society scoring system, as described. ${ }^{12}$ Endometrial biopsies and resection of endometriotic ovarian cysts were performed with the patient under anesthesia. All subjects provided written informed consent under a protocol approved by the Committee on Human Research at the University of California, San Francisco.

\section{Immunohistochemistry}

Endometrial tissue specimens were fixed for 24 hours in Histochoice MB (Amresco, Solon, OH), paraffin embedded, and cut in serial sections of $8 \mu \mathrm{m}$. Sections were stained with a rabbit polyclonal anti-human VEGF-A antiserum (Santa Cruz Antibodies, Santa Cruz, CA) at a concentration of $10 \mu \mathrm{g} / \mathrm{ml}$ using the Vectastain Elite ABC kit (Vector Laboratories, Burlingame, CA). Negative controls for immunostaining were performed using normal rabbit serum at the identical protein concentration $(10 \mu \mathrm{g} / \mathrm{ml})$, as described previously. ${ }^{13}$ Immunostaining for polymorphonuclear granulocytes was performed using mouse monoclonal antibodies against human neutrophil elastase $(2 \mu \mathrm{g} / \mathrm{ml}$, Zymed, So. San Francisco, CA). Negative controls for immunostaining were performed using an irrelevant, isotype-specific mouse monoclonal antibody (anti-synaptophysin) at the identical protein concentration $(2 \mu \mathrm{g} / \mathrm{ml})$, as described previously. ${ }^{14,15}$ The chromagen signal was enhanced with $\mathrm{NiSO}_{4}$ using the Liquid Diaminobenzidine-Black Substrate kit (Zymed, South San Francisco, CA).

\section{Establishment of Human Endometrial Cell Cultures}

The techniques for isolation and culture of human endometrial and endometriotic stromal cells in vitro were described in detail elsewhere. ${ }^{12}$ Briefly, follicular phase endometrial biopsies from control women were used to prepare cultures of normal 
endometrial cells, and endometriotic ovarian cysts were used as the source of endometriotic cells. The specimens were minced, digested with collagenase, and serially filtered through narrow gauge sieves with apertures of $38-105 \mu \mathrm{m}$ to trap the glandular epithelium. Stromal cells were plated and allowed to adhere to plastic cellculture dishes for 30 minutes, at which time contaminating epithelial and blood cells and tissue debris were rinsed free. Epithelial cells were backwashed from the cell sieves and plated onto Matrigel-coated culture wells. Stromal cells were subcultured twice to eliminate contamination by immunocytes. All experiments were performed with cells at passage zero (epithelium) or two (stroma), within 14 days of initial isolation. Under these conditions the primary cells retain estrogen receptor (ER) mRNA and protein. ${ }^{12,16}$ Purity of the epithelial and stromal cell populations was confirmed by positive immunostaining for cytokeratin and vimentin, respectively, using specific mouse anti-human monoclonal antibodies. ${ }^{12}$

\section{Polarized Endometrial Epithelial Cell Cultures}

In some experiments, human proliferative phase endometrial epithelial cells were grown under polarizing conditions. ${ }^{17}$ Primary endometrial epithelial cells were prepared from biopsies, as described above, and plated onto polyethylene terephthalate Transwell culture inserts with a pore size of $0.4 \mu \mathrm{m}$ (Becton Dickinson, Lincoln Park, NJ). The cells were cultured in MEM- $\alpha$ reconstituted with $10 \%$ fetal calf serum (FCS), nucleosides, essential amino acids, $100 \mathrm{U} / \mathrm{ml}$ penicillin $\mathrm{G}$, and $100 \mu \mathrm{g} /$ $\mathrm{ml}$ streptomycin.

\section{Steroid and Cytokine Treatment}

Prior studies documented the presence of ER- $\alpha$ and ER- $\beta$ mRNA and functional ER proteins in endometrial stromal cells cultured in vitro. ${ }^{16}$ Confluent cultures of endometrial stromal cells and Ishikawa adenocarcinoma cells were incubated overnight in low-serum medium (phenol red-free MEM- $\alpha$ supplemented with $2.5 \%$ dextran-charcoal stripped FBS, nucleosides, antibiotics, and nonessential amino acids) and exposed to 10 or $100 \mathrm{nM} \mathrm{E} \mathrm{E}_{2}$ or vehicle (ethanol) control for an additional 24 hours. The latter concentration was used in Ishikawa cells transfected with the human ER- $\alpha$ cDNA (HEO), as this construct carries a point mutation that renders the $K_{\mathrm{d}} \sim 70 \%$ higher than that of the wild-type ER. ${ }^{18}$

Similar experiments were performed in primary endometrial stromal cells using $10 \mathrm{ng} / \mathrm{ml}$ IL-1 $\beta$ (R\&D Systems, Minneapolis, MN) or $100 \mathrm{ng} / \mathrm{ml}$ tumor necrosis factor (TNF) $-\alpha$ and interferon (IFN)- $\gamma$ (Sigma Chemical Co., St. Louis, MO). All the cytokines were recombinant human proteins, to which the endometrial stromal cells were exposed for up to 24 hours. These doses previously were shown to optimally induce IL-6 ${ }^{19}$ and RANTES (regulated on activation, normal T-cell expressed and secreted $)^{20}$ expression in primary endometrial stromal cell cultures.

\section{Quantification of VEGF-A Protein and $\mathrm{mRNA}$}

At the end of each experiment, conditioned media were aspirated and centrifuged to pellet floating cells, and the supernatants were assayed for secreted VEGF 165 using a sensitive sandwich ELISA developed at Genentech, Inc. (South San Francisco, CA). ${ }^{13}$ The cells were lysed in TriZOL reagent (Gibco-BRL, Gaithersburg, MD), 
and total RNA was isolated and subjected to formaldehyde gel electrophoresis. Northern blotting with random-primed $\left[\alpha-{ }^{32} \mathrm{P}\right] \mathrm{dCTP}-$ labeled VEGF and glyceraldehyde-3-phosphate dehydrogenase (GAPDH) cDNA probes was performed as described. ${ }^{15}$ In some experiments with Ishikawa cells, semiquantitative reverse transcription-polymerase chain reaction (RT-PCR) assays were used to estimate the concentration of VEGF-A mRNA relative to GAPDH mRNA. ${ }^{15}$ Actinomycin D, an inhibitor of DNA-dependent RNA synthesis, was used at a concentration of $5 \mu \mathrm{g} / \mathrm{ml}$ to prove that mRNA accumulation was the result of transcriptional, rather than posttranscriptional, control. ${ }^{21}$

\section{Quantification of VEGF-A Gene Promoter Activity}

VEGF-A promoter-luciferase reporter constructs were designed as described ${ }^{22}$ and contained $2.3 \mathrm{~kb}$ of the human VEGF-A gene promoter upstream of firefly luciferase cDNA in the pGL2 reporter vector (Promega, Minneapolis, MN). These plasmids were transiently transfected into primary endometrial epithelial and stromal cells and into Ishikawa adenocarcinoma cells by calcium phosphate precipitation, lipofection, and electroporation, respectively, as described. ${ }^{22}$

\section{Data Analysis and Statistics}

The data are expressed as the mean \pm SEM. Paired Student's $t$ tests were used. Statistical significance was accepted at $p<0.05$ for two-tailed analyses.

\section{RESULTS}

Immunohistochemical staining of endometrial biopsy specimens from normal women revealed both epithelial and stromal expression of VEGF-A, as we and others reported previously. ${ }^{13,23}$ Typically, the epithelial staining pattern was more prominent, with secretory vacuoles showing concentrated VEGF-A protein (FIG. 1A). Endometrial stromal cells were labeled more diffusely for VEGF-A, with an appearance suggestive of extracellular matrix localization of the protein (FIG. 1A). Isolated round cells within the endometrial stroma (arrow) and endometrial vessels (arrowhead) also were stained brightly by the anti-VEGF-A antiserum (FIG. 1A). These cells were identified as polymorphonuclear granulocytes by their intense reaction with human neutrophil elastase antibodies in adjacent sections (FIG. 1B). Double immunoenzymatic labeling techniques, described elsewhere, proved that the same cells coexpressed human neutrophil elastase and VEGF-A. ${ }^{15}$

Monolayers of primary endometrial epithelial cells were established in bicameral chambers. ${ }^{20}$ The development of high electrical resistance $\left(868 \pm 53 \Omega / \mathrm{cm}^{2}\right.$, mean \pm SD) and the establishment of a gradient of $\left[{ }^{125} \mathrm{I}\right]$ ovalbumin added to the upper chamber of the epithelial cell-lined Transwell inserts verified the integrity of the polarized endometrial epithelial monolayer. In these cells we noted a fivefold higher ratio of apical to basal VEGF secretion $(p<0.05)$. By contrast, directional secretion of a soluble isoform of fibronectin was not statistically different in the same cells (FIG. 2).

Other in vitro models were established to investigate the regulation of VEGF-A mRNA and protein in these cells. Endometrial stromal cells cultured in the presence 


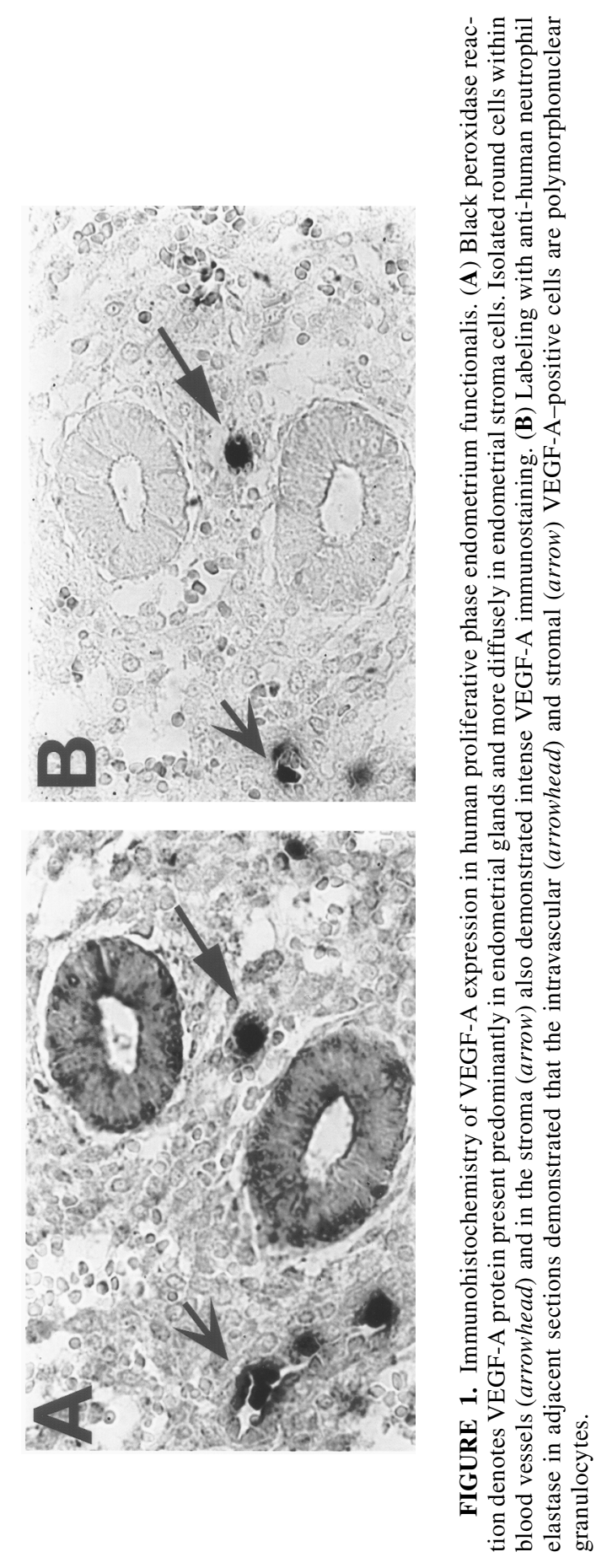


TABLE 1. Estradiol effects on VEGF mRNA accumulation in endometrial cells

\begin{tabular}{lcc}
\hline \multicolumn{1}{c}{ Cell type } & Hormone treatment & $\begin{array}{c}\text { VEGF mRNA } \\
\text { (arbitrary units) }\end{array}$ \\
\hline Endometrial stromal cells & Control $(0.1 \%$ ethanol) & 1.0 \\
Ishikawa cells & $10 \mathrm{nM} \mathrm{E}_{2}$ & $3.1 \pm 1.8^{a}$ \\
& Control & 1.0 \\
Ishikawa cells transfected with ER- $\alpha$ & $100 \mathrm{nM} \mathrm{E}_{2}$ & $1.1 \pm 0.5$ \\
& Control & 1.0 \\
& $100 \mathrm{nM} \mathrm{E}_{2}$ & $2.0 \pm 0.2^{a}$ \\
\hline
\end{tabular}

${ }^{a} p<0.05$ (paired Student's $t$ test).

of $10 \mathrm{nM} \mathrm{E}_{2}$, to mimic the endocrine milieu of the late proliferative phase, showed an increase in VEGF-A mRNA accumulation (3.1-fold increase; TABLE 1). Ishikawa cells expressed basal levels of VEGF-A mRNA, but these did not change after exposure to up to $100 \mathrm{nM} \mathrm{E}$. However, following transfection with physiological concentrations of functional human ER- $\alpha$ (HEO, 20,000 receptors/cell), treatment with $100 \mathrm{nM} \mathrm{E}_{2}$ caused a 2.0-fold stimulation in steady-state levels of VEGF-A transcripts (TABLE $1^{15}$ ).

Exposure of normal endometrial stromal cells to IL-1 $\beta$ had no effect on steadystate VEGF transcript concentrations (TABLE 2) and failed to increase VEGF secretion by these cells. Likewise, treatment of the stromal cells with TNF- $\alpha$ and IFN- $\gamma$ for 24 hours failed to induce VEGF protein secretion. ${ }^{21}$ By contrast, endometriotic stromal cells, derived from ovarian endometrioma tissue, manifested a three- to fourfold upregulation of VEGF-A mRNA accumulation and protein secretion after exposure to IL-1 $\beta$. The former effect was blocked by preincubation with actinomycin $\mathrm{D}$, an inhibitor of mRNA synthesis, indicating a transcriptional mechanism of action.

Direct transcriptional regulation of the VEGF-A gene was examined by transfecting VEGF-A promoter-luciferase vectors into primary endometrial epithelial and stromal cells by calcium phosphate precipitation and lipofection, respectively. Reporter plasmids containing $2.3 \mathrm{~kb}$ of the human VEGF-A gene promoter were tested in primary endometrial epithelial and stromal cells and in the Ishikawa adenocarci-

TABLE 2. Cytokine effects on VEGF mRNA accumulation in endometrial cells

\begin{tabular}{lccc}
\hline Cell type & Hormone treatment & $\begin{array}{c}\text { VEGF mRNA } \\
\text { (arbitrary units) }\end{array}$ & $\begin{array}{c}\text { VEGF secreted } \\
(\mathrm{pg} / \mathrm{ml})\end{array}$ \\
\hline Endometrial stromal cells & Control & 1.0 & $64 \pm 34$ \\
& $0.6 \mathrm{nM} \mathrm{IL}-1 \beta$ & $0.8 \pm 0.1$ & $45 \pm 7$ \\
Endometriosis stromal cells & Control & 1.0 & $162 \pm 93$ \\
& $0.6 \mathrm{nM} \mathrm{IL}-1 \beta$ & $2.6 \pm 0.2^{a}$ & $671 \pm 470^{a}$ \\
\hline
\end{tabular}

$a_{p}<0.05$ (paired Student's $t$ test). 


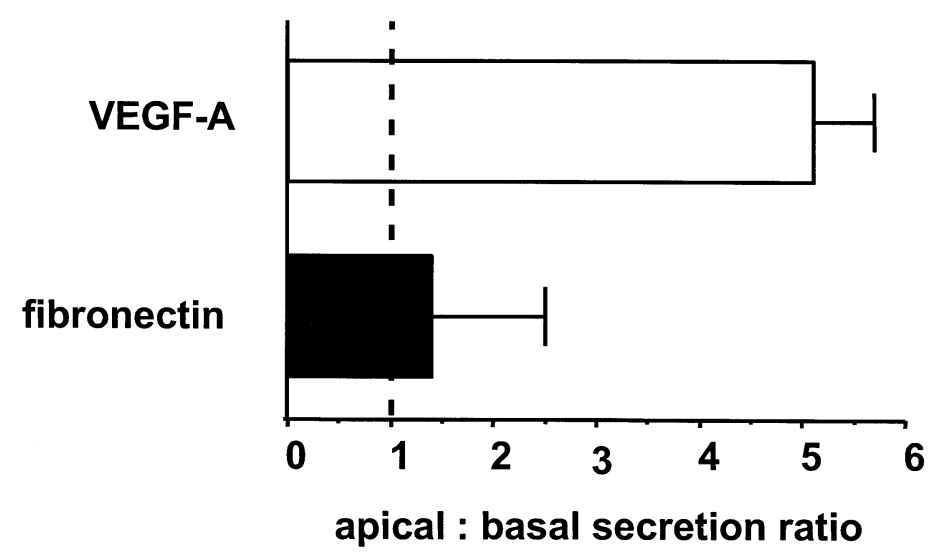

FIGURE 2. Vectorial secretion of VEGF-A from polarized endometrial epithelial cells. VEGF-A was secreted preferentially into the apical compartment of Transwell chambers (open histogram), whereas fibronectin secretion (closed histogram) was similarly distributed into the apical and basal chambers.

noma cell line. ${ }^{22}$ Treatment with $10 \mathrm{nM} \mathrm{E} 2$ induced a three- to fourfold activation of the promoter in both endometrial epithelial and stromal cells (FIG. 3, histograms 1 and 2). Transfection of the same construct into Ishikawa adenocarcinoma cells failed to respond to $\mathrm{E}_{2}$ at concentrations up to $100 \mathrm{nM}$ (FIG. 3, histogram 3). However, cotransfection of vectors expressing functional human $\mathrm{ER}-\alpha$, restored $\mathrm{E}_{2}$ responsiveness of the VEGF-A gene promoter (FIG. 3, histogram 4).

\section{DISCUSSION}

Although changes in endometrial capillary proliferation and permeability are modulated during the ovarian cycle and with exogenous steroids, endothelial cells per se may not be direct targets of classical ER $(\alpha)$ or progesterone receptormediated effects. Receptors for these steroids are present in human uterine artery smooth muscle, but have not been identified convincingly in endothelium in situ. ${ }^{24,25}$ Using the highly sensitive reverse transcriptase-PCR approach, we ${ }^{26}$ and others ${ }^{27}$ were unable to detect either ER- $\alpha$ or ER- $\beta$ mRNAs in human umbilical vein endothelium. However, functional evidence of ER-mediated gene activation and gel mobility shift assays have been reported by some investigators using these cells. ${ }^{28}$ Nuclear progesterone receptors have been reported in murine endothelial cells ${ }^{29}$ and human endometrial endothelium. ${ }^{30}$ In general, however, it is believed that ovarian steroid effects on angiogenesis are mediated indirectly via the paracrine actions of prostaglandins or polypeptide growth factors derived from nearby endometrial epithelial or stromal cells.

Findings in the current study confirm previous results from ourselves ${ }^{13}$ and others $^{31}$ that VEGF-A gene expression is upregulated in isolated human endometrial cells by $\mathrm{E}_{2}$. This endocrine milieu models that observed in the late proliferative 


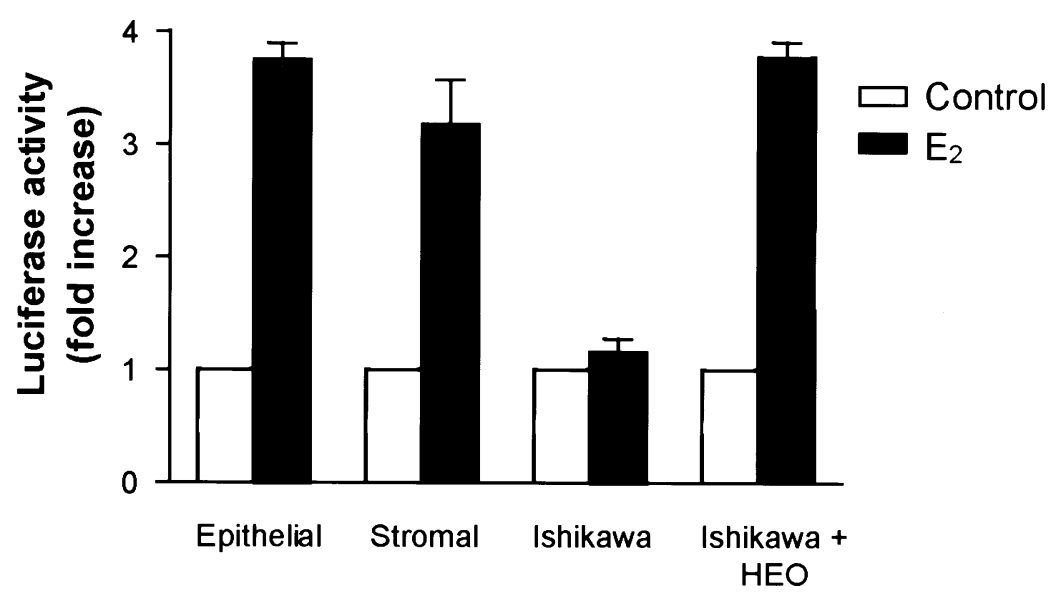

FIGURE 3. Estradiol induction of VEGF-A promoter-luciferase activity in primary endometrial epithelial cells, primary endometrial stromal cells, and nontransfected and ER- $\alpha$ transfected (HEO) Ishikawa adenocarcinoma cells.

phase of the menstrual cycle. Estrogens upregulate VEGF mRNA and protein production in uterine tissues and cells. If similar results are confirmed in endometriotic tissues, these studies support the obligatory role of estrogen on endometriosis implants $^{32}$ and the observation that downregulating doses of GnRH analogues, which diminish circulating $\mathrm{E}_{2}$ levels, also decrease the size and vascularity of endometriosis lesions. ${ }^{33}$ However, while microvascular growth and VEGF-A expression are temporally correlated within the endometrium, a clear correlation between VEGF intensity and markers of endothelial cell proliferation is disputed. ${ }^{34}$ It is likely that coexpression of other angiogenic factors and substrates (e.g., basic FGF, VEGF receptors, or angiopoietins) also are required for full vascularization of this tissue.

The apical localization in situ and secretion in vitro of VEGF-A remain a curious observation. We have proposed that this angiogenic factor also may affect blastocyst function. Hemochorial placentation, such as that observed in human pregnancy, is associated with the development of an endothelial-like phenotype of trophoblastic cells. ${ }^{35}$ Invasive first trimester human cytotrophoblasts and cultured choriocarcinoma cells both express the flt- 1 and KDR receptors for VEGF-A. ${ }^{36}$ Hence, endometrial luminal VEGF-A may provide a trophic signal to the implanting human blastocyst.

Using the same in vitro cell model, we failed to observe effects of IL-1 $\beta$ (IL-1 $\beta$ ), TNF- $\alpha$, and IFN- $\gamma$ on VEGF expression in normal endometrial stromal cells, despite the known actions of all three cytokines on other bioactive proteins (e.g., IL- $6^{19}$ and RANTES $^{20}$ ). However, we did observe that cytokines can increase VEGF-A mRNA and protein expression in stromal cells derived from endometriotic lesions. Thus, proinflammatory cytokines are mediators of neovascularization in endometriotic implants. 
It is unlikely that ovarian steroids are direct mediators of endometrial angiogenesis. Most investigators have failed to identify detectable levels of classical estrogen $(\alpha)$ or progesterone (A and B) receptors in endometrial vascular endothelial cells. ${ }^{25,37}$ However, in some recent reports, immunohistochemistry and RT-PCR demonstrated estrogen and progesterone receptor expression in human endometrial endothelial cells. ${ }^{29,30}$ In the latter study, progesterone-receptor complexes were reported to inhibit mitotic activity of endothelial cells. Further studies will be needed to clarify whether some endothelial cells have direct ovarian steroid responses.

The cloned human VEGF gene promoter consists of $2.4 \mathrm{~kb}$ of DNA upstream from the transcription start site and a long $5^{\prime}$ untranslated region. ${ }^{38}$ Initiation of VEGF mRNA synthesis is modulated by sequence-specific consensus sites that bind transcriptional control factors. Analyses of the primary sequence of the VEGF promoter reveal several common response elements, including: AP-1, AP-2, and hypoxia-induced enhancer sequences in this gene. ${ }^{39-43}$

Although no consensus palindromic estrogen response element (ERE) sequence exists in the 2.4-kb VEGF promoter, $\mathrm{E}_{2}$ treatment increases VEGF mRNA as early as 1 hour after hormone administration, suggesting a direct regulation of VEGF gene transcription. ${ }^{13}$ VEGF gene expression also has been shown to be regulated rapidly by $E_{2}$ in the rat uterus. ${ }^{44}$ We recently identified a functional variant ERE about $1.5 \mathrm{~kb} \mathrm{5}$ to the transcription initiation site of the human gene promoter, ${ }^{22}$ and Hyder and colleagues ${ }^{44}$ reported an estrogen-dependent element in the $3^{\prime}$ untranslated region of the VEGF-A gene.

Estrogen-receptor complexes classically bind as dimers to consensus, 13-bp palindromic EREs. ${ }^{45}$ Although few natural genes contain perfect palindromic EREs, ER complexes also can activate components of the AP-1 complex (e.g., $c$-fos and $c$ $j u n)^{46}$ or bind imperfect EREs if a GATA- 6 sequence is present nearby. ${ }^{39}$ As described herein, IL-1 $\beta$ can upregulate VEGF in endometriotic stromal cells and has been demonstrated in other cell types. ${ }^{47}$ It has been postulated that this cytokine effect is mediated via NFKB motifs located in the VEGF promoter. ${ }^{48}$ This hypothesis is under examination currently in our laboratory.

In summary, we propose that endocrine and paracrine modulation of endometrial angiogenesis is mediated via transcriptional upregulation of VEGF-A gene expression in endometrial stromal and epithelial cells. VEGF-A is an angiogenic factor of hierarchical importance, particularly in the uterus, where it responds to multiple stimuli. Steroids, cytokines, and chemokines, by virtue of their recruitment of VEGF-A-producing inflammatory cells, allow fine-tuning of endometrial vascularization. Interruption of single or multiple pathways within this complex network should provide therapeutic opportunities for the amelioration of vascular abnormalities associated with endometrial disorders such as endometriosis and dysfunctional uterine bleeding.

\section{ACKNOWLEDGMENTS}

These studies were supported by National Institutes of Health Grants HD33238 (RNT) and HD08517 (DIL), the Deutsche Forschungsgemeinschaft Ho-1832/2-1 (DH), and the Swiss National Science Foundation (MDM). The authors thank Dale Leitman, Evelyn Garrett, Mary Matli and Victor Chao (UCSF), and Napoleone Fer- 
rara and Gloria Meng (Genentech, So. San Francisco) for their generous assistance with this project and Julia Qi-Turner for preparing the manuscript.

\section{REFERENCES}

1. Folkman, J.\& M. Klagsburn. 1987. Angiogenic factors. Science 235: 442-447.

2. Ferrara, N. et al. 1992. Molecular and biological properties of the vascular endothelial growth factor family of proteins. Endocrine Rev. 13: 18-32.

3. Torry, D.S. et al. 1996. Vascular endothelial growth factor expression in cycling human endometrium. Fertil. Steril. 66: 72-80.

4. Huang, J.C., D. Y. LiU \& M.Y. Dawood. 1998. The expression of vascular endothelial growth factor isoforms in cultured human endometrial stromal cells and its regulation by 17beta-oestradiol. Mol. Hum. Reprod. 4: 603-607.

5. Markee, J. 1940. Menstruation in intraocular endometrial transplants in the rhesus monkey. Contrib. Embryol. 177: 221-308.

6. Noyes, R.W., A.T. Hertig \& J. Rock. 1950. Dating the endometrial biopsy. Fertil. Steril. 1: 3-25.

7. FANGer, H. \& B.E. BARKer. 1961. Capillaries and arterioles in normal endometrium. Obstet. Gynecol. 17: 543-550.

8. Ferenczy, A., G. Bertrand \& M. Gelfand. 1979. Proliferation kinetics of human endometrium during the normal mentrual cycle. Am. J. Obstet. Gynecol. 133: 859867.

9. Rogers, P.A., F. LEDERMAn \& N. TAYLOR. 1998. Endometrial microvascular growth in normal and dysfunctional states. Hum. Reprod. Update 4: 503-508.

10. NELSON, K. et al. 1991. Epidermal growth factor replaces estrogen in the stimulation of female genital-tract growth and differentiation. Proc. Natl. Acad. Sci. USA 88: 21-25.

11. Kaiserman-Abramof, I. \& H. Padykula. 1989. Angiogenesis in the postovulatory primate endometrium: the coiled arteriolar system. Anat. Rec. 224: 479-489.

12. RYAN, I., E. SCHRIOCK \& R. TAYLOR. 1994. Isolation, characterization and comparison of human endometrial and endometriosis cells in vitro. J. Clin. Endocrinol. Metab. 78: $642-649$.

13. SHIFREN, J. et al. 1996. Ovarian steroid regulation of vascular endothelial growth factor in the human endometrium: implications for angiogenesis during the menstrual cycle and in the pathogenesis of endometriosis. J. Clin. Endocrinol. Metab. 81: 3112-3118.

14. HoRnung, D. et al. 1997. Immunolocalization and regulation of the chemokine RANTES in human endometrial and endometriosis tissues and cells. J. Clin. Endocrinol. Metab. 82: 1621-1628.

15. MuelLER, M.D. et al. 2000. Neutrophils infiltrating the endometrium express vascular endothelial growth factor: potential role in endometrial angiogenesis. Fertil. Steril. 74: $107-112$.

16. BRAndEnBerger, A.W. et al. 1999. Oestrogen receptor (ER)- $\alpha$ and ER- $\beta$ isoforms in normal endometrial and endometriosis-derived stromal cells. Mol. Hum. Reprod. 5: 651-655.

17. WANG, G.M.J. \& S.R. Glasser. 1996. Effects of tamoxifen and ICI 164384 on protein synthesis and vectorial secretion in polarized rat uterine epithelial cells. J. Steroid Biochem. Mol. Biol. 58: 307-317.

18. Tora, L.M.A., D. Metzger, M. Ponglikitmongkol, et al. 1989. The cloned human oestrogen receptor contains a mutation which alters its hormone binding properties. EMBO J. 8: 1981-1986.

19. TSENG, J. et al. 1996. Interleukin-6 secretion in vitro is up-regulated in ectopic and eutopic endometrial stromal cells from women with endometriosis. J. Clin. Endocrinol. Metab. 81: 1118-1122.

20. Hornung, D., J.-L. Vigne \& R.N. TAYlor. 1998. RANTES derived from normal endometrial and endometriosis stromal cells has altered bio- to immunoactivity. J. Soc. Gynecol. Invest. 5: 18. 
21. LeBovic, D.I. et al. 2000. Induction of an angiogenic phenotype in endometriotic stromal cell cultures by interleukin-1beta. Mol. Hum. Reprod. 6: 269-275.

22. Mueller, V.J., A. Minchenko, D.I. Lebovic, et al. 2000. Regulation of vascular endothelial growth factor (VEGF) gene transcription by estrogen receptors alpha and beta. Proc. Natl. Acad. Sci. USA 97: 10972-10977.

23. Donnez, J. et al. 1998. Vascular endothelial growth factor (VEGF) in endometriosis. Hum. Reprod. 13: 1686-1690.

24. Perrot-Applanat, M. et al. 1988. Immunocytochemical demonstration of estrogen and progesterone receptors in muscle cells of uterine arteries in rabbits and humans. Endocrinology 123: 1511-1519.

25. TAYLOR, R.N. et al. 1999. Ovarian steroids and angiogenesis. In Understanding and Managing Endometriosis. A. Lemay \& R. Maheux, eds.: 131-137. Parthenon. London.

26. BAKER, V.L. et al. 1997. Human umbilical vessels and cultured umbilical vein endothelial and smooth muscle cells lack detectable protein and mRNA encoding estrogen receptors. J. Soc. Gynecol. Invest. 4: 316-324.

27. JENSEN, I. et al. 1998. Human umbilical vein endothelial cells lack expression of the estrogen receptor. Endothelium 6: 9-21.

28. Kim-Schulze, S. et al. 1996. Expression of an estrogen receptor by human coronary artery and umbilical vein endothelial cells. Circulation 94: 1402-1407.

29. VAZQuez, F., J.C. Rodriguez-ManZaneque, J.P. Lydon, et al. 1999. Progesterone regulates proliferation of endothelial cells. J. Biol. Chem. 274: 2185-2192.

30. Iruela-Arispe, M., C.A. Diglio \& E.H. SAGE. 1991. Modulation of extracellular matrix proteins by endothelial cells undergoing angiogenesis in vitro. Arterioscler. Thromb. 11: 805-815.

31. Sмiтh, S. 1998. Angiogenesis, vascular endothelial growth factor and the endometrium. Hum. Reprod. Update 4: 509-519.

32. DiZerega, G., D. Barber \& G. Hodgen. 1980. Endometriosis: role of ovarian steroids in initiation, maintenance, and suppression. Fertil. Steril. 33: 649-653.

33. SCHRIOCK, E. et al. 1985. Treatment of endometriosis with a potent agonist of gonadotropin-releasing hormone (nafarelin). Fertil. Steril. 44: 583-588.

34. GargetT, C.E. et al. 1999. Lack of correlation between vascular endothelial growth factor production and endothelial cell proliferation in the human endometrium. Hum. Reprod. 14: 2080-2088.

35. DAMSKY, C.H. \& S.J. FishER. 1998. Trophoblast pseudo-vasculogenesis: faking it with endothelial adhesion receptors. Curr. Opin. Cell Biol. 5: 660-666.

36. Charnock-Jones, D.S. et al. 1994. Vascular endothelial growth factor receptor localization and activation in human trophoblast and choriocarcinoma cells. Biol. Reprod. 51: 524-530.

37. Perrot-Applanat, M., M. Deng, H. Fernandez, et al. 1994. Immunohistochemical localization of estradiol and progesterone receptors in human uterus throughout pregnancy: expression in endometrial blood vessel. J. Clin. Endocrinol. Metab. 78: 216-224.

38. TisCHER, E. et al. 1991. The human gene for vascular endothelial growth factor: multiple protein forms are encoded through alternative exon splicing. J. Biol. Chem. 266: 11947-11954.

39. Davis, D.L. \& J.B.E. Burch. 1996. The chicken vitellogenin II gene is flanked by a GATA factor-dependent estrogen response unit. Mol. Endocrinol. 10: 937-944.

40. Garrido, C., S. Saule \& D. Gospodarowicz. 1993. Transcriptional regulation of vascular endothelial growth factor gene expression in ovarian bovine granulosa cells. Growth Factors 8: 109-117.

41. Klein-Hitpaß, L. et al. 1988. A 13 bp palindrome is a functional estrogen responsive element and interacts specifically with estrogen receptor. Nucl. Acids Res. 16: 647663.

42. VON DER AHE, D. et al. 1985. Glucocorticoid and progesterone receptors bind to the same sites in two hormonally regulated promoters. Nature 313: 706-709.

43. Welter, J.F. et al. 1995. Fos-related Antigen (Fra-1), junB, and junD activate human involucrin promoter transcription by binding to proximal and distal AP1 sites to 
mediate phorbol ester effects on promoter activity. J. Biol. Chem. 270: 12614 12622.

44. HYDER, S.M. et al. 2000. Identification of functional estrogen response elements in the gene coding for the potent angiogenic factor vascular endothelial growth factor. Cancer Res. 60: 3183-3190.

45. Kumar, V. \& P. Chambon. 1988. The estrogen receptor binds tightly to its responsive element as a ligand-induced homodimer. Cell 55: 145-156.

46. PAECH, K. et al. 1997. Differential ligand activation of estrogen receptors ERalpha and ERbeta at AP1 sites. Science 277: 1508-1510.

47. Ryuto, M. et al. 1996. Induction of vascular endothelial growth factor by tumor necrosis factor alpha in human glioma cells. Possible roles of SP-1. J. Biol. Chem. 271: 28220-28228.

48. RoYDS, J.A. et al. 1998. Response of tumour cells to hypoxia: role of p53 and NFkB. Mol. Pathol. 51: 55-61. 